\title{
Role of individual nap gene cluster products in NapC-independent nitrate respiration of Wolinella succinogenes
}

\author{
Melanie Kern, Anke M. Mager and Jörg Simon \\ Institute of Molecular Biosciences, Johann Wolfgang Goethe University, Max-von-Laue-Strasse 9, \\ 60438 Frankfurt am Main, Germany
}

Correspondence

Jörg Simon

j.simon@bio.uni-frankfurt.de

Received 18 May 2007

Revised 22 June 2007

Accepted 28 June 2007
Bacterial nap gene clusters, encoding periplasmic nitrate reductase ( $\mathrm{NapA})$, are complex and diverse, and the composition of the electron transport chain donating electrons to NapA is poorly characterized in most organisms. Exceptionally, Wolinella succinogenes transfers electrons from formate via the menaquinone pool to NapA independently of a membrane-bound c-type cytochrome of the NapC family. The role of individual ORFs of the $W$. succinogenes napAGHBFLD gene cluster is assessed here by characterizing in-frame gene inactivation mutants. The ability of the mutants to grow by nitrate respiration was tested and their NapA content and specific nitrate reductase activity were determined. The nap $B$ and nap $D$ gene products proved to be essential for nitrate respiration, with NapD being required for the production of mature NapA. Inactivation of either subunit of the putative membrane-bound menaquinol dehydrogenase complex NapGH almost abolished growth by nitrate respiration. Substitution of the twin-arginine sequence of NapG had the same effect as absence of NapG. Phenotypes of mutants lacking either NapF or NapL suggest that both proteins function in NapA assembly and/or export. The data substantiate the current model of the composition of the NapCindependent electron transport chain as well as of NapA maturation, and indicate the presence of an alternative electron transport pathway to NapA.

\section{INTRODUCTION}

Prokaryotes are able to synthesize three distinct types of nitrate reductase that all reduce nitrate to nitrite but serve different physiological functions (for reviews see Lin \& Stewart, 1998; Potter et al., 2001; Richardson et al., 2001; González et al., 2006). Two nitrate reductases (Nar and Nap) terminate respiratory electron transport chains, while the cytoplasmic Nas enzyme is involved in assimilatory nitrate reduction. The Nar enzyme is bound to the membrane with the active site of nitrate reduction facing the cytoplasm, whereas Nap is located in the periplasmic space of Gram-negative bacteria. Electrons transported to Nar or Nap derive from the membranous quinol pool. The catalytic subunit of the periplasmic nitrate reductase (NapA) usually receives electrons from the dihaem $c$-type cytochrome NapB. Depending on the stability of interaction between NapA and NapB, heterodimeric nitrate reductases $(\mathrm{Nap} A B)$ and monomeric nitrate reductases (NapA) have been reported (Jepson et al., 2006, 2007; Arnoux et al., 2003). In most cases NapB is thought to be reduced by NapC, a membrane-bound tetrahaem cytochrome $c$ that is thought to catalyse quinol oxidation. $\mathrm{NapC}$ is prototypic for members of the NapC/NirT/NrfH

Abbreviations: BV, benzyl viologen; Tat, twin-arginine translocase. family, which mediate electron transfer in various anaerobic respiratory chains (Roldán et al., 1998; Simon et al., 2000, 2001; Gross et al., 2005; Rodrigues et al., 2006). More recently, a putative membrane-bound complex consisting of the two predicted iron-sulfur proteins, NapG and $\mathrm{NapH}$, was proposed to be functionally equivalent to NapC (Richardson et al., 2001; Simon et al., 2003, 2004). NapG and $\mathrm{NapH}$ are likely to make up a quinol dehydrogenase that transports electrons from the quinone pool to a periplasmic $c$-type cytochrome, i.e. NapB or NapM (see below) (Brondijk et al., 2002, 2004; Jepson et al., 2006). The putative NapGH complex has been shown in Escherichia coli to function as a ubiquinol dehydrogenase that transfers electrons from ubiquinol via NapC to $\mathrm{NapAB}$, while NapC catalyses menaquinol oxidation independently of NapGH (Brondijk et al., 2004). Apparently, napG and napH genes are present when napC is lacking. The composition of bacterial nap operons is diverse (Marietou et al., 2005; González et al., 2006). While the napA and napD genes seem to be present throughout, NapF, NapL and NapM are encoded less frequently. NapF and NapD are predicted to be cytoplasmic proteins that function in NapA maturation (Berks et al., 1995; Olmo-Mira et al., 2004; Nilavongse et al., 2006). To date, NapL has been found only in nap operons of $\varepsilon$ proteobacteria, while NapM is a multihaem cytochrome $c$ 
that is encoded in some nap operons lacking napB (Jepson et al., 2006). The functional role of both NapL and NapM is unclear.

Like many other bacteria, the $\varepsilon$-proteobacterium Wolinella succinogenes grows by anaerobic respiratory nitrate ammonification, using formate or $\mathrm{H}_{2}$ as electron donor substrates (Bokranz et al., 1983; Lorenzen et al., 1993; for reviews see Kröger et al., 2002; Simon, 2002). This mode of respiration is dependent on two terminal reductases, periplasmic nitrate reductase (NapA) and cytochrome $c$ nitrite reductase (NrfA). Mutants deficient in napA or in nrfA do not grow by nitrate and nitrite respiration, respectively (Simon et al., 2000, 2003). The W. succinogenes genome sequence does not predict any other obvious nitrate- or nitrite-reducing enzyme (Baar et al., 2003). It has been demonstrated that $W$. succinogenes nitrate respiration is independent of a NapC-like protein, since a mutant lacking both NapC homologues encoded in the genome (NrfH and FccC) grows by nitrate respiration and exhibits wild-type growth parameters (Simon et al., 2003). Together with NrfA, the $\mathrm{NrfH}$ protein forms a membrane-bound complex that catalyses nitrite reduction using menaquinone as electron donor (Simon et al., 2000).

The $W$. succinogenes genome contains a rather unusual napAGHBFLD gene cluster (Simon et al., 2003). A model of the electron transport chain of $W$. succinogenes nitrate respiration has been proposed in which one or more of the $n a p F, G, H$ and $L$ gene products mediate(s) electron transport from menaquinol to the periplasmic NapAB complex, hence substituting for the function conventionally carried out by NapC (Simon et al., 2003). The function of each nap gene product is tested here by characterizing a set of in-frame deletion mutants each defective in a single nap gene situated downstream of napA.

\section{METHODS}

Growth of W. succinogenes. W. succinogenes cells were grown by nitrate respiration in medium $(\mathrm{pH} 7.5)$ containing Tris $(50 \mathrm{mM})$, sodium formate $(80 \mathrm{mM})$, potassium nitrate $(50 \mathrm{mM}), \mathrm{K}_{2} \mathrm{HPO}_{4}$ (1 $\mathrm{mM})$, fumaric acid $(5 \mathrm{mM})$, ammonium sulfate $(5 \mathrm{mM}), \mathrm{MgCl}_{2}$ $(1 \mathrm{mM}), \mathrm{CaCl}_{2}(0.2 \mathrm{mM})$, glutamic acid $(0.68 \mathrm{mM})$, cysteine $(0.57 \mathrm{mM})$ and trace element solution $\left(0.2 \mathrm{ml} \mathrm{l}^{-1}\right)$, as used by Pfennig \& Trüper (1981). Brain-heart infusion broth $(0.25$ or $0.5 \%$, $\mathrm{w} / \mathrm{v}$ ) was added where appropriate. Growth by fumarate respiration was performed in the medium described by Kröger et al. (1994). Where indicated, $20 \mathrm{mM}$ potassium nitrate was added.

Cell fractionation. W. succinogenes cells harvested in the exponential growth phase were suspended $\left(10 \mathrm{~g}\right.$ cell protein $\left.\mathrm{l}^{-1}\right)$ in an anoxic buffer ( $\mathrm{pH} 8.0$ ) containing $50 \mathrm{mM}$ Tris/HCl. The suspension was passed through a French press at $130 \mathrm{MPa}$ and $10 \mathrm{ml} \mathrm{min}^{-1}$ flow rate. The resulting cell homogenate was centrifuged for $45 \mathrm{~min}$ at $100000 \mathrm{~g}$ to yield the membrane fraction (sediment) and the soluble fraction.

Determination of specific enzyme activities, and analytical procedures. Nitrate reductase activity was measured under anoxic conditions at $37{ }^{\circ} \mathrm{C}$ by photometrically recording the oxidation of reduced benzyl viologen (BV) by nitrate at $546 \mathrm{~nm}$. The test solution contained $50 \mathrm{mM}$ potassium phosphate ( $\mathrm{pH} 7.0), 1 \mathrm{mM} \mathrm{BV}$ and $10 \mathrm{mM}$ sodium nitrate. BV was reduced by sodium dithionite and the reaction was started by addition of nitrate. Specific activities were calculated using an extinction coefficient $(\varepsilon)$ of $19.5 \mathrm{mM}^{-1} \mathrm{~cm}^{-1}$. For each micromole nitrate reduced to nitrite, $2 \mu \mathrm{mol}$ BV were oxidized. Protein was measured using the Biuret method with KCN (Bode et al., 1968). Nitrate, nitrite and formate (using $\mathrm{NAD}^{+}$and formate dehydrogenase) were determined as described elsewhere (Hartley \& Asai, 1963; Rider \& Mellon, 1946; Bergmeyer, 1974).

Construction of $\boldsymbol{W}$. succinogenes mutants. Standard genetic procedures were used (Sambrook et al., 1989). DNA was isolated from W. succinogenes using the DNeasy Tissue kit (Qiagen). PCR was carried out using BIOTAQ DNA polymerase (Bioline) or the Expand High Fidelity PCR System (Roche) with standard amplification protocols. W. succinogenes $\Delta n a p G-D$ was constructed using a deletion plasmid in order to replace the genomic napGHBFLD region by a chloramphenicol resistance gene (cat) cartridge according to a strategy outlined previously (Simon et al., 2000). The deletion plasmid $\mathrm{p} \Delta$ napG-D contained the cat gene flanked by two PCR fragments identical to regions of the $W$. succinogenes genome. The two PCR fragments were obtained using the following primer pairs: 5'-CGGAATTCACCTGAGATGCCTAGTAGCG-2911 and 5'-CGGGATCCCCGCTCCTAAAGCCCTTAGGC-3262 for amplifying the upstream fragment; and 5'-CGGGATCCGAGGAGCTAGAGCTAGAGCGCC-7164 and 5'-ACGCGTCGACGGGGCTCATTCTCGCGTCTCC-7658 for the downstream fragment. The primers carried an EcoRI, BamHI or SalI restriction site (underlined) for cloning. The numbers at the $3^{\prime}$ ends of the primer sequences correspond to the nucleotide positions in the EMBL, GenBank and DDBJ database (accession number AJ512686). Transformation of W. succinogenes wild-type cells (DSMZ 1740) with p $\Delta$ napG-D was carried out by electroporation, as described previously (Simon et al., 2000), except that transformants were selected on agar plates containing formate/ fumarate medium and $12.5 \mathrm{mg}$ chloramphenicol $\mathrm{l}^{-1}$. The desired substitution in the transformant genome was confirmed by PCR and Southern blot analysis employing suitable nap and cat probes (not shown). The deleted region comprises the entire nap $G, H, B, F$ and $L$ genes as well as $225 \mathrm{bp}$ of the $5^{\prime}$ end of napD (64\% of the gene).

In order to restore the complete nap gene cluster on the genome of $W$. succinogenes $\Delta$ nap $G-D$, plasmid pnapG-Dkan was constructed, which contained $36 \%$ of napA ( $3^{\prime}$ end) as well as the complete nap $G, H, B$, $F, L$ and $D$ genes (Fig. 1). The nap region was present on a PCR fragment amplified with the primer pair 5'-ACGCGTCGACCCCCGTAGGAAATGCGATGCC-2297 and 5'-TCCCCGGCCGGGGGCTCATTCTCGCGTCTCC-7658; see above for numbering. The primers carried a SalI or XmaIII restriction site (underlined) for cloning. The resulting $5.4 \mathrm{~kb}$ fragment was incorporated into a derivative of pBR322 containing a cat gene inserted into its unique BamHI site. Sequencing of the entire nap insert revealed two singlenucleotide mutations in napH (positions 4818 and 4826) that were corrected by site-directed mutagenesis using the QuikChange sitedirected mutagenesis kit (Stratagene) and an appropriate primer pair (sequences not shown). The single BamHI site of the nap insert (positions 2886-2891) was silently mutated to GGACCC to allow the subsequent replacement of cat by a kanamycin resistance gene cartridge (kan; obtained by BamHI excision from pUC4K). PCR analysis showed that plasmid pnapG-Dkan contained the kan gene in the same orientation as the nap cluster (Fig. 1). After electroporation of $W$. succinogenes $\Delta n a p G-D$ cells with pnapG-Dkan, transformants were selected in formate/fumarate medium containing $50 \mathrm{mM}$ nitrate, $25 \mathrm{mg}$ kanamycin $\mathrm{l}^{-1}$ and $12.5 \mathrm{mg}$ chloramphenicol $\mathrm{l}^{-1}$. The desired integration of the plasmid into the genome was confirmed by PCR and Southern blot analysis (not shown). The correctness of the $991 \mathrm{bp}$ napA sequence involved in plasmid 


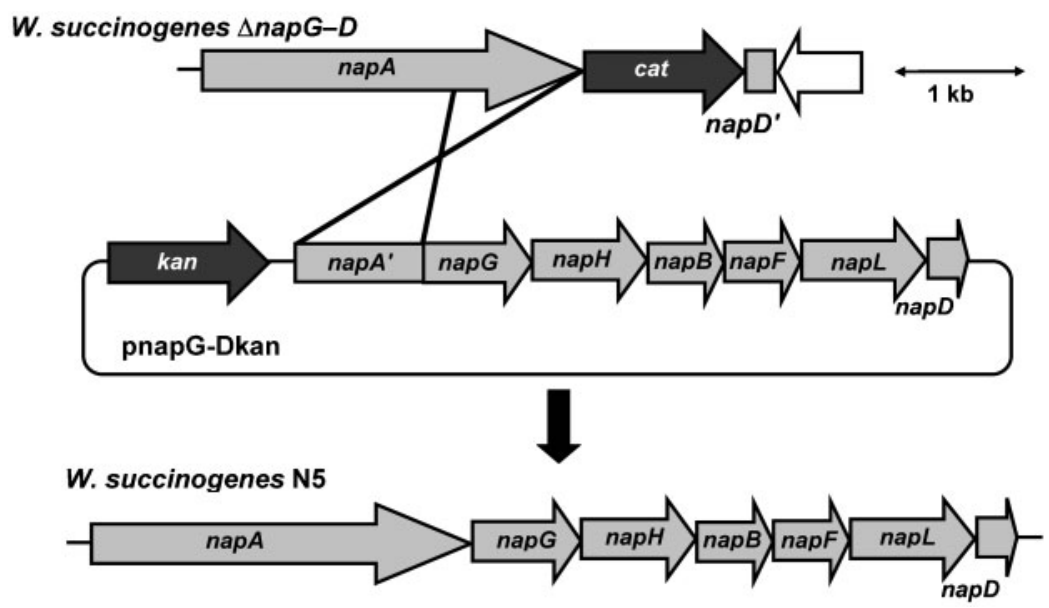

Fig. 1. Restoration of the complete nap operon on the genome of $W$. succinogenes $\Delta$ nap $G-D$ through homologous recombination using plasmid pnapG-Dkan. See Methods for details.

integration was proven by amplification and sequencing of an appropriate PCR product.

Site-directed mutagenesis of nap genes was performed using the QuikChange site-directed mutagenesis kit and pnapG-Dkan (or a derivative) as a template. A pair of complementary primers was used for each modification, for which the forward primer sequences $\left(5^{\prime} \rightarrow 3^{\prime}\right)$ were as follows; stop-napG-1, GGATGATGAAAGAGCTTTAATGAGACGAACGGAGG-3318; stop-napG-2, GGAGCACCCCTTGATAAATGTGCGAGGATATTCC-3596; stop-napH-1, GAAATTTTTAAAACACTAATGATTCTTACTCCTTCGG-4123; stop-napH2, GGGGCTTCCCGCCTAATAGTTTATCAGCCC-4533; stop-napB1, GGTTGCATCCACGTGATAGGCTTTAGCCTTC-4970; stopnapF-1, GGTTTTTCACCTCTCTTTAGTGATCCAAAAGGG-5513; stop-napF-2, GGGGATGCACCTTTTGATAAGCATGTGCGCTTGCC-5707; stop-napL-1, CCCTCTATCTCATCTAATGAGTCACTCTCTTGG-6010; stop-napL-2, CCCCCTAAAATCTAATGAATCGATACACTCG-6232; stop-napD-1, GAATATTTCTAGTGTTGTTTGATAGGTCAAGCCCGAGG-6957; RRnapG, CAATCAGACGAACGGGGGGGGGTTATCCTAGG-3329 (see above for numbering). The altered nucleotides are indicated in bold type and the modified codons are underlined (see Table 1 for details of modified codons and encoded residues). Transformation of $W$. succinogenes $\Delta n a p G-D$ cells with plasmid derivatives and genetic characterization of the transformants were performed as described above. In addition, each mutation was confirmed by sequencing of an appropriate PCR fragment. The preservation of desired stop codons was routinely confirmed after growth experiments.

W. succinogenes $\Delta$ nos $G-H$ kan was constructed using a deletion plasmid in order to replace the genomic nosGC1C2H region by a kanamycin resistance gene cartridge ( $k a n$ ) by a similar strategy to that described above. The deletion plasmid $\mathrm{p} \Delta$ nosG-H contained the kan gene flanked by two PCR fragments identical to regions in the $W$. succinogenes genome. The two PCR fragments were obtained using the following primer pairs: 5'-CGGAATTCCTATTTGAGCGCAACTCTGTGGGG-181303 and 5'-CGGGATCCCAAAATTTCGCCTCCATTTTGGGC-181855 for amplifying the upstream fragment; and 5'-CGGGATCCAAGAGCCAAAAGGAGAAACTATTGATTG-184541 and $5^{\prime}$-ACGCGTCGACCATGGCAAACTCTCTCAAAAGCGC185042 for the downstream fragment. The primers carried an EcoRI, BamHI or SalI restriction site (underlined) for cloning. The numbers at the $3^{\prime}$ ends of the primer sequences correspond to the nucleotide positions given in the EMBL, GenBank and DDBJ database (accession number BX571659). The desired substitution in $W$. succinogenes transformants (selected on formate/nitrate medium with $25 \mathrm{mg}$ kanamycin $\mathrm{l}^{-1}$ ) was confirmed by PCR analysis employing suitable nos and kan primers (not shown). The deleted region starts with the nos $G$ start codon and comprises each nos $G$ and nos $H$ codon up to and including the nosH stop codon.

\section{RESULTS AND DISCUSSION}

\section{In-frame inactivation of $W$. succinogenes nap genes}

A set of nap mutants was generated as described in Methods and illustrated in Fig. 1. First, $W$. succinogenes $\Delta n a p G-D$ was constructed, which lacks the nap $G, H, B, F$, $L$ and part of the napD genes. In a second step the entire nap operon was restored on the genome of this mutant upon integration of pnapG-Dkan, resulting in the presence of one copy of the nap operon located at its genuine genomic position under the control of the wild-type nap promoter (Fig. 1). The mutant containing the restored wild-type nap operon ( W. succinogenes N5) showed wildtype properties with respect to growth by nitrate respiration, specific nitrate reductase activity and NapA content (Tables 1 and 2, Fig. 2). In contrast, the $\Delta$ napG-D mutant did not grow by nitrate respiration and lacked NapA-dependent nitrate reductase activity when grown under fumarate-respiring conditions. The phenotype of the latter mutant resembled that of the NapA-deficient strain $W$. succinogenes napA::kan (Simon et al., 2003). Interestingly, the $\Delta n a p G-D$ mutant did not synthesize an immunodetectable form of NapA, demonstrating that at least one of the other nap gene products is essential for the synthesis of folded and functional NapA (Fig. 2). During nitrate respiration, wild-type cells produced nitrite at a concentration that almost corresponded to the concentration of nitrate degraded (Fig. 3a). Only about $5 \mathrm{mM}$ nitrite was converted to ammonium before formate was exhausted, indicating that there was only a minor contribution of nitrite respiration to total cell growth under these growth conditions. Like $W$. succinogenes $n a p A:: k a n$, the $\Delta n a p G-D$ mutant did not reduce nitrate and no nitrite was produced (Fig. $3 \mathrm{~b}$ ). 
Table 1. Growth parameters of $W$. succinogenes nap gene cluster mutants

Representative data from at least two independent cultures are shown.

\begin{tabular}{|c|c|c|c|c|c|}
\hline \multirow[t]{2}{*}{ Strain } & \multirow[t]{2}{*}{ Modification $^{*}$} & \multicolumn{2}{|c|}{$\begin{array}{c}\text { Growth parameters on minimal } \\
\text { medium }^{\dagger}\end{array}$} & \multicolumn{2}{|c|}{$\begin{array}{c}\text { Growth parameters on supple- } \\
\text { mented medium }\end{array}$} \\
\hline & & $\begin{array}{l}\text { Doubling } \\
\text { time }(h)\end{array}$ & $\begin{array}{l}\text { Final optical } \\
\text { density }(\%)\end{array}$ & $\begin{array}{l}\text { Doubling } \\
\text { time }(h)\end{array}$ & $\begin{array}{l}\text { Final optical } \\
\text { density }(\%)\end{array}$ \\
\hline Wild-type & None & 2.5 & 100 & 2.0 & 100 \\
\hline$\Delta n a p G-D$ & Deletion of napGHBFLD region & $\infty$ & 0 & $\infty$ & 0 \\
\hline N5 & Restored wild-type nap gene cluster & 2.6 & 100 & 2.0 & 100 \\
\hline stopnap $G$ & NapG: Q6stop, S7stop, C98stop, Y99stop & 3.8 & 3 & 3.8 & 16 \\
\hline $\mathrm{RR} n a p G$ & NapG: R11G, R12G & 4.4 & 3 & 4.2 & 14 \\
\hline stopnapH & NapH: Y7stop, R8stop, F145stop, E146stop & 2.7 & 8 & 2.5 & 23 \\
\hline stopnapB & NapB: G16stop, L17stop & $\infty$ & 0 & $\infty$ & 0 \\
\hline stopnapF & NapF: L11stop, R12stop, C74stop, Q75stop & 4.7 & 36 & 2.3 & 44 \\
\hline stopnapL & NapL: L11stop, G12stop, F85stop, G86stop & 6.3 & 113 & 4.0 & 121 \\
\hline stopnapD & NapD: A8stop, K9stop & $\infty$ & 0 & $\infty$ & 0 \\
\hline$\Delta n o s G-H$ & Deletion of $\operatorname{nos} G C 1 C 2 \mathrm{H}$ & 2.5 & 100 & 2.0 & 100 \\
\hline
\end{tabular}

${ }^{*}$ See Methods for details of mutant construction.

$\dagger$ Cells were incubated at $37{ }^{\circ} \mathrm{C}$ in anoxic minimal medium containing formate $(80 \mathrm{mM})$ and nitrate $(50 \mathrm{mM})$ as energy substrates in the presence of $10 \mathrm{mM}$ ammonium. Fumarate $(5 \mathrm{mM})$, present as a carbon source, allowed limited growth by fumarate respiration during the initial stage (2$3 \mathrm{~h}$ ) of growth. Cultures were inoculated using cells grown in the same medium supplemented with $0.25 \%$ (w/v) brain-heart infusion broth. Doubling times were calculated from the exponential growth phase. The $\mathrm{OD}_{578}$ of wild-type cells entering the stationary phase was typically about 0.55 (corresponding to $100 \%$ ), while that of mutant cells unable to grow by nitrate respiration was 0.08 (set as $0 \%$ ). All growing cultures became stationary after 7-9 h. $\infty$, No growth.

$\ddagger$ Cells were grown as described above, except that the medium was supplemented with $0.25 \%$ (w/v) brain-heart infusion broth. Cultures were inoculated with cells grown in formate/fumarate medium supplemented with $50 \mathrm{mM}$ potassium nitrate and $0.5 \%$ (w/v) brain-heart infusion broth. The $\mathrm{OD}_{578}$ of wild-type cells entering the stationary growth phase was typically about 0.6 (corresponding to $100 \%$ ), while that of mutant cells unable to grow by nitrate respiration was 0.09 (set as $0 \%$ ).

Individual nap genes were inactivated on pnapG-Dkan by introducing consecutive stop codons into the predicted ORFs at their $5^{\prime}$ ends and, in some cases, also in their central regions (Table 1). W. succinogenes mutants containing the respective modified plasmids integrated into their genomes were characterized (see Table 1 for mutant nomenclature).

\section{Role of NapB}

The mutant defective in napB neither grew by nitrate respiration nor did it reduce nitrate, indicating that NapB is an essential component in the respiratory chain of nitrate respiration (Table 1, Fig. 3c). The absence of NapB in cell extracts of the stopnapB mutant was confirmed by

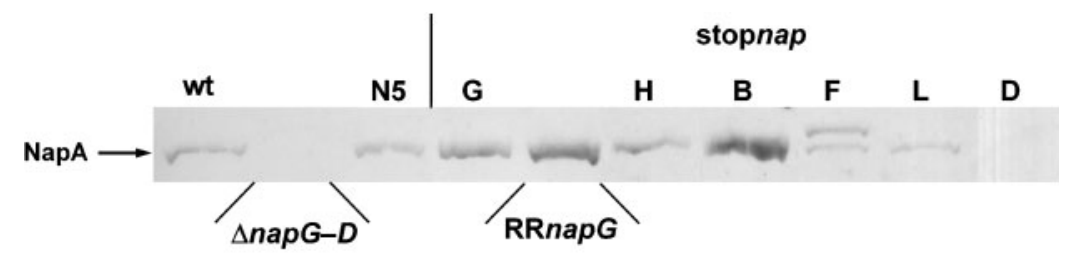

Fig. 2. Immunodetection of $\mathrm{NapA}$ in cell homogenates of $W$. succinogenes wild-type (wt) and nap mutants. Cells were grown in the medium described in Table 2. SDS-PAGE was performed with $80 \mu \mathrm{g}$ protein applied to each lane. For Western blot analysis, protein was transferred from the SDS gel to nitrocellulose by electroblotting in a discontinuous buffer system (Kyhse-Andersen, 1984). The NapA antigen was detected by indirect ELISA using an antiserum raised against NapA from Paracoccus pantotrophus (Berks et al., 1994) and goat anti-rabbit lgG coupled to peroxidase (Cell Signaling Technology). 

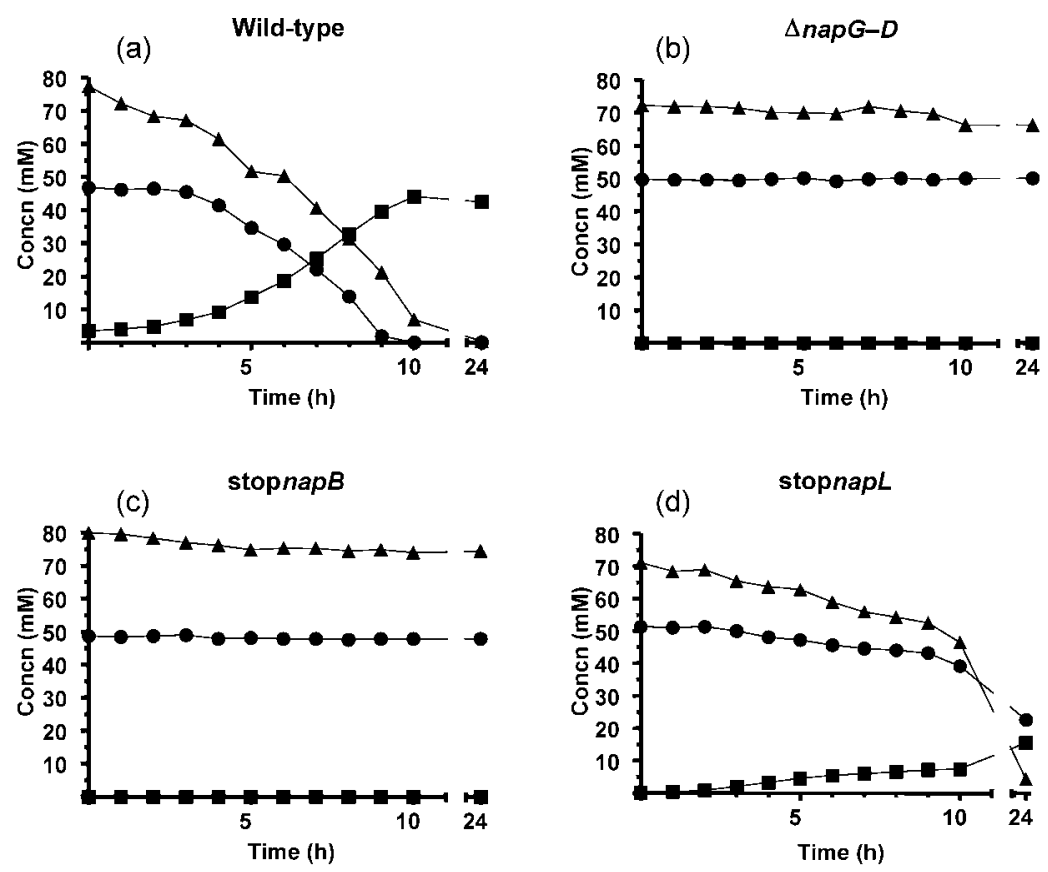

(e) stopnapG

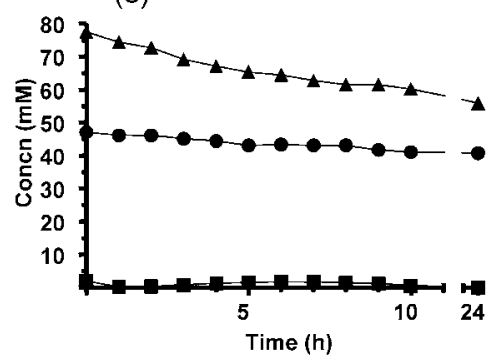

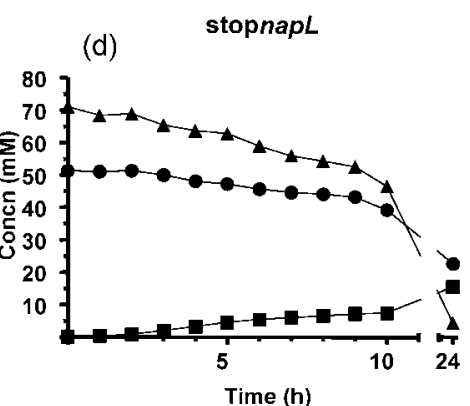

(f)

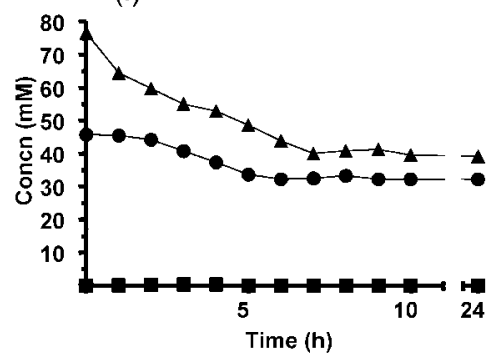

Fig. 3. Time-course of nitrate, nitrite and formate concentrations during incubation of different strains in minimal formate/nitrate medium (see Table 1). (O) Nitrate, (ם) nitrite, (A) formate. peroxidase-linked haem staining of cell proteins after separation by denaturing PAGE (not shown). Compared with the wild-type, stopnapB contained an increased amount of NapA as detected by immunoblot analysis (Fig. 2) and had nearly double the specific nitrate reductase activity using reduced BV as electron donor, with excess NapA being located in the soluble cell fraction (Table 2). The reason for the apparent overproduction is not known. The results demonstrate that both the formation of NapA and its capacity for nitrate reduction by reduced BV are independent of the presence of its redox partner NapB. Notably, W. succinogenes stopnapB retained a considerable amount of nitrate reductase activity in the membrane fraction, indicating that membrane attachment of NapA occurred independently of NapB. Active NapA devoid of a NapB redox partner has been described in Desulfovibrio desulfuricans, and there are other known nap operons that lack napB (Dias et al., 1999; Jepson et al., 2006). It has been speculated that in such cases, NapG might functionally replace NapB (Jepson et al., 2006). Assuming that the nap gene products other than $\mathrm{NapB}$ are present in wild-type amounts in stopnapB, the results indicate that there is no physiologically relevant electron transport from NapG (or NapGH) to NapA in W. succinogenes. In Rhodobacter sphaeroides and E. coli the napB gene has also been found to be essential for nitrate reduction in vivo (Reyes et al., 1998; Potter \& Cole, 1999). The napB-deficient mutant of $R$. sphaeroides even lacks notable nitrate reductase activity using reduced methyl viologen as the electron donor (Reyes et al., 1998).

\section{Role of NapD}

A NapD homologue is encoded in every nap gene cluster currently known. Cytoplasmic NapD has been postulated to function as a NapA-specific chaperone probably involved in insertion of the molybdenum bis-molybdopterin guanine dinucleotide cofactor into NapA prior to twin-arginine translocase (Tat)-dependent export of folded NapA into the periplasmic space (Berks et al., 1995; Palmer et al., 2005). W. succinogenes stopnapD did not grow by nitrate respiration (Table 1 ) demonstrating that NapD is 
Table 2. Specific nitrate reductase activity of $W$. succinogenes wild-type cells and nap gene cluster mutants

Representative values from at least two independent cultures are given.

\begin{tabular}{|c|c|c|c|c|}
\hline \multirow[t]{2}{*}{ Strain } & \multicolumn{4}{|c|}{$\begin{array}{c}\text { Specific nitrate reductase activity } \mathrm{BV}_{\text {red }} \rightarrow \text { nitrate }^{\star}[\mu \mathrm{mol} \text { nitrate } \\
\left.\text { reduced } \min ^{-1}(\mathrm{mg} \text { cell protein })^{-1}\right]\end{array}$} \\
\hline & Intact cells & Cell homogenate & Membrane fraction & Soluble fraction \\
\hline Wild-type $\dagger$ & 1.8 & 1.8 & 0.9 & 1.1 \\
\hline$\Delta n a p G-D$ & 0.08 & $0.3 \ddagger$ & $0.3 \ddagger$ & 0.06 \\
\hline N5 & 1.6 & 1.7 & 0.9 & 1.2 \\
\hline stopnapG & 1.6 & 1.6 & 1.0 & 1.2 \\
\hline $\mathrm{RR} n a p G$ & 1.9 & 1.9 & 0.7 & 1.0 \\
\hline stopnapH & 1.4 & 1.5 & 0.9 & 1.0 \\
\hline stopnapB & 3.6 & 3.7 & 1.3 & 2.6 \\
\hline stopnapF & 1.3 & 1.2 & 0.8 & 0.9 \\
\hline stopnapL & 0.4 & 0.2 & 0.3 & 0.3 \\
\hline stopnapD & 0.5 & 0.5 & 0.8 & 0.14 \\
\hline$\Delta n o s G-H$ & 1.6 & 1.8 & 1.2 & 1.0 \\
\hline
\end{tabular}

${ }^{\star}$ Cells were grown in medium containing formate $(100 \mathrm{mM})$, fumarate $(90 \mathrm{mM})$ and nitrate $(20 \mathrm{mM})$ as energy substrates, and supplemented with $0.5 \%(\mathrm{w} / \mathrm{v})$ brain-heart infusion broth. Cells and membrane fractions were suspended in an anoxic buffer ( $\mathrm{pH} 7.5)$ containing $50 \mathrm{mM}$ Tris/HCl.

$\dagger$ Specific enzyme activities taken from Simon et al. (2003). Note that a considerable portion of activity is located in the membrane fraction (Simon et al., 2003).

$¥$ NapA-independent nitrate reduction activity. Such an activity has been reported previously for $W$. succinogenes napA:: kan cells (Simon et al., 2003).

an essential component of the W. succinogenes Nap system, as has been found in other organisms (Reyes et al., 1998; Potter \& Cole, 1999). NapA was not detectable in $W$. succinogenes stopnapD and the specific nitrate reductase activity of the mutant was similar to that of the napA:: kan mutant (Fig. 2, Table 2). This activity is assigned to an as yet unknown second enzyme that reduces nitrate using BV but not formate as an electron donor (Simon et al., 2003). The results can be explained by NapD serving in either NapA stabilization or folding and are in agreement with its proposed function as a twin-arginine signal chaperone for NapA.

\section{Role of NapL}

The NapL protein is predicted to be a soluble protein, but its precise localization and function are unknown. The $n a p L$ gene seems to be restricted to nap operons of $\varepsilon^{-}$ proteobacterial genera, i.e. Wolinella, Campylobacter, Helicobacter and Sulfurimonas (Simon et al., 2003; Pittman et al., 2007). The stopnapL mutant of $W$. succinogenes exhibits a clearly reduced doubling time and nitrate consumption rate, although the cells eventually reached the optical density of wild-type cells in the stationary growth phase (Table 1, Fig. 3d). The specific nitrate reductase activity of the stopnapL mutant was significantly lower than that of the wild-type (Table 2), although the mutant cells contained only a slightly reduced amount of NapA (Fig. 2). The results indicate that NapL plays a role in NapA maturation or function in an as yet unknown manner. Recently, a NapL-deficient mutant of Campylobacter jejuni was described (Pittman et al., 2007). This mutant is not affected in growth with nitrate and has a normal nitrite accumulation rate, although it possesses only about half of the wild-type nitrate reductase activity using reduced $\mathrm{BV}$ as the electron donor. This points to a similar function of NapL in W. succinogenes and C. jejuni, and suggests a decreased stability or catalytic efficiency of NapA. Such a role might be taken over by other proteins in organisms that lack a napL gene. NapL is predicted to be synthesized with a putative Sec signal peptide, but its cellular location is unknown. An attempt to raise a peptide antiserum suitable for detecting $W$. succinogenes NapL was not successful.

\section{Role of NapF}

The NapF proteins from R. sphaeroides and E. coli have been described recently as cytoplasmic iron-sulfur proteins that are possibly involved in the incorporation of the NapA [4Fe-4S] cluster (Olmo-Mira et al., 2004; Nilavongse et al., 2006). In E. coli the napF gene was found to be dispensable for nitrate reduction using either glycerol or formate as the growth substrate (Potter \& Cole, 1999). W. succinogenes stopnapF grew by nitrate respiration, albeit with an increased doubling time as compared with wild-type cells 
(Table 1). Furthermore, the mutant cells did not reach the final optical density of wild-type cells (Table 1). Western blot analysis revealed the presence of two distinct immunodetectable forms of NapA in stopnapF cells (Fig. 2 ). The larger form presumably represents the cytoplasmic NapA precursor awaiting export by the Tat system. The specific nitrate reductase activity was slightly lower than that of wild-type cells, indicating that functional NapA is still assembled even in the absence of NapF. Taken together, it seems that NapA maturation is retarded in the absence of NapF, supporting the hypothesis that NapF indeed plays a role in iron-sulfur cluster assembly, possibly supporting the capacity of the conventional iron-sulfur cluster maturation machinery (the NifSU system). Interestingly, many Campylobacter species lack a napF gene in their nap clusters, thus underlining the proposed accessory role for NapF.

\section{Roles of NapG and NapH}

The putative NapGH complex has been postulated to be a prime candidate for catalysing NapC-independent menaquinol oxidation and electron transfer to $\mathrm{NapAB}$ in $W$. succinogenes (Simon et al., 2003). The W. succinogenes nap $G$ and $n a p H$ genes were individually inactivated (Table 1). In addition, mutant RRnapG was constructed, whose NapG protein contains two glycine residues instead of the two conserved arginine residues of the putative Tat signal sequence. In supplemented medium all three mutants showed only residual growth by nitrate respiration. In minimal medium, growth of the stopnap $G$ and RRnap $G$ mutants was even more severely impaired. Under these conditions, the stopnap $G$ and stopnapH mutants slowly consumed only about 6 and $11 \mathrm{mM}$ nitrate, respectively, before both growth and nitrate reduction stopped (Fig. 3e, f). No nitrite accumulation occurred, indicating that the small amount of nitrite produced was instantly reduced to ammonium. The total amount of formate converted was in agreement with this assumption, as four molecules of formate are required to reduce one molecule of nitrate to ammonium. The results indicate the functional importance of NapG and $\mathrm{NapH}$ as well as that of the twin-arginine sequence of NapG for nitrate respiration, but also indicate the existence of a less efficient alternative electron transport route capable of electron transfer to NapA. Periplasmic localization of NapG is very likely, as has been indicated for E. coli NapG (Brondijk et al., 2004). It is notable that some bacteria lack the twin-arginine residues in NapG, and it was hypothesized that in this case NapG is co-exported with NapA (Jepson et al., 2006). The NapA protein and specific NapA-dependent nitrate reductase activity is retained in stopnapG, stopnapH and RRnapG mutants (Table 2 and Fig. 2), indicating that NapG and $\mathrm{NapH}$ are not involved in NapA maturation or function, in contrast to NapF, NapL and NapD. The similar phenotypes of the stopnapG and stopnapH mutants suggest that NapG and NapH are components of the same functional unit.

\section{Alternative routes for menaquinol oxidation and electron transfer to NapA}

There are several proteins encoded on the $W$. succinogenes genome that might participate in electron transport to NapA (via NapB) in the absence of either NapG or NapH. The most obvious candidates are NosG and NosH, which are homologous to their Nap counterparts (Simon et al., 2004). The nos $G$ and nos $H$ genes are part of the nos locus, which encodes cytochrome $c$ nitrous oxide reductase (NosZ). Both the nosGC1C2H and napGH transcripts were detected in RT-PCR experiments using wild-type cells grown with either nitrate or fumarate (results not shown). Quantitative real-time RT-PCR revealed that the transcript levels of nosG, nosC1, nosC2 and nosH were not significantly increased in stopnap $G$ and stopnapH mutants when compared with wild-type cells (results not shown). This is not surprising, as nos $Z$ is known to be disrupted by a copy of insertion element IS1302 (Simon et al., 2004). Hence, constitutive transcription of the nos $G, C 1, C 2$ and $H$ genes, situated downstream of nos $Z$, is likely to be initiated from a promoter located within IS1302, e.g. that of the transposase gene tnpA (Simon \& Kröger, 1998). Accordingly, all four nos genes mentioned above were found not to be upregulated during transition from fumarate to nitrate respiration, in contrast to nap and $n r f$ genes (A. M. Mager \& J. Simon, unpublished data).

In a different approach, the nos $G C 1 C 2 \mathrm{H}$ region was deleted from the genome of $W$. succinogenes wild-type cells. The nos $C 1$ and nos $C 2$ genes encode monohaem $c$-type cytochromes of unknown function (Simon et al., 2004). Compared with wild-type cells, the resulting mutant $W$. succinogenes $\Delta$ nos $G-H$ did not show any notable difference during growth with nitrate, nitrite or fumarate as the electron acceptor with respect to growth parameters and substrate turnover, and no difference in nitrate reductase activity or NapA content was observed (Tables 1 and 2, data not shown).

Taken together, it cannot be excluded that nos gene products participate in electron transport to NapA. In principle, however, any periplasmic iron-sulfur protein or $c$-type cytochrome might slowly reduce NapB (and hence NapA) in the absence of NapGH. When present, the latter clearly works as the physiological electron donor within the Nap system. Due to limitations of functional marker genes, it was not possible to delete nos genes in W. succinogenes stopnap $G$ or stopnapH.

A nap $G$ mutant of $C$. jejuni has been described as having a phenotype similar to that of $W$. succinogenes stopnap $G$ (Pittman et al., 2007). In the case of $C$. jejuni, residual growth by nitrate respiration is abolished upon additional inactivation of $n r f H$, the gene encoding the quinoloxidizing subunit of the cytochrome $c$ nitrite reductase complex (NrfHA), a member of the NapC/NirT family (Pittman et al., 2007; Gross et al., 2005). In W. succinogenes, $\mathrm{NrfH}$ is known to form a tight and stable complex with $\mathrm{NrfA}$, the pentahaem cytochrome $c$ nitrite reductase 
(Simon et al., 2000; Simon, 2002), a feature that is also supported by the crystal structure of the Desulfovibrio vulgaris $\mathrm{NrfHA}_{2}$ complex (Rodrigues et al., 2006). As NrfA is formed in excess over $\mathrm{NrfH}$ in nitrate-grown $W$. succinogenes cells, it is unlikely that free $\mathrm{NrfH}$ donates electrons to a Nap component (Simon et al., 2000). It cannot be excluded, however, that the NrfHA complex slowly feeds some electrons into the Nap system, possibly via NapB, thus bypassing NapG or NapGH. A $W$. succinogenes mutant lacking nrfHA has been described as not being affected in nitrate respiration (Simon et al., 2003). For the reasons stated above, deletion of $n r f H$ in stopnap $G$ or stopnapH is not feasible at present.

\section{Conclusions}

The results presented here underpin the existing model of NapA-dependent bacterial nitrate respiration of $W$. succinogenes (see Fig. 3 in Simon et al., 2003) and demonstrate that each nap gene product has a functional role in this metabolic pathway. The work further supports the view that various electron transfer pathways exist that form a network in the periplasmic space, thus making it difficult to determine the contribution of individual components. Despite numerous efforts, we did not succeed in setting up a biochemical assay to determine the specific electron transport activity from formate or a water-soluble menaquinone analogue to nitrate using intact cells or membranes of W. succinogenes. Any measured activity was much lower than the physiological minimal nitrate reduction rate calculated from growth rate and molar cell yield. We believe, however, that such an activity is accurately reflected here by the presented growth properties and changes in substrate concentrations. Future experiments will aim at the overproduction of tagged NapG and NapH proteins in order to directly demonstrate protein-protein and protein-quinol interactions.

\section{ACKNOWLEDGEMENTS}

The authors are grateful to Dr Roland Gross for helpful discussions and Monica Sänger for excellent technical assistance. Professor David J. Richardson is acknowledged for generously hosting J.S. at the University of East Anglia, Norwich, UK, and for providing antiParacoccus pantotrophus NapA serum. This work was supported by the SFB 472 'Molecular Bioenergetics' (projects P5 and P33) of the Deutsche Forschungsgemeinschaft (DFG) and by the Center for Membrane Proteomics (CMP) at the University of Frankfurt am Main. J. S. holds a DFG Heisenberg Fellowship.

\section{REFERENCES}

Arnoux, P., Sabaty, M., Alric, J., Frangioni, B., Guigliarelli, B., Adriano, J.-M. \& Pignol, D. (2003). Structural and redox plasticity in the heterodimeric periplasmic nitrate reductase. Nat Struct Biol 10, 928-934.

Baar, C., Eppinger, M., Raddatz, G., Simon, J., Lanz, C., Klimmek, O., Nandakumar, R., Gross, R., Rosinus, A. \& other authors (2003). Complete genome sequence and analysis of Wolinella succinogenes. Proc Natl Acad Sci U S A 100, 11690-11695.
Bergmeyer, H. U. (1974). Methoden der enzymatischen Analyse. Weinheim: Verlag Chemie.

Berks, B. C., Richardson, D. J., Robinson, C., Reilly, A., Aplin, R. T. \& Ferguson, S. J. (1994). Purification and characterization of the periplasmic nitrate reductase from Thiosphaera pantotropha. Eur J Biochem 220, 117-124.

Berks, B. C., Richardson, D. J., Reilly, A., Willis, A. C. \& Ferguson, S. J. (1995). The napEDABC gene cluster encoding the periplasmic nitrate reductase system of Thiosphaera pantotropha. Biochem J 309, 983-992.

Bode, C., Goebell, H. \& Stähler, E. (1968). Zur Eliminierung von Trübungsfehlern bei der Eiweißbestimmung mit der Biuretmethode. Z Klin Chem Klin Biochem 6, 418-422 (in German).

Bokranz, M., Katz, J., Schröder, I., Roberton, A. M. \& Kröger, A. (1983). Energy metabolism and biosynthesis of Vibrio succinogenes growing with nitrate or nitrite as terminal electron acceptor. Arch Microbiol 135, 36-41.

Brondijk, T. H. C., Fiegen, D., Richardson, D. J. \& Cole, J. A. (2002). Roles of NapF, NapG and NapH, subunits of the Escherichia coli periplasmic nitrate reductase, in ubiquinol oxidation. Mol Microbiol 44, 245-255.

Brondijk, T. H. C., Nilavongse, A., Filenko, N., Richardson, D. J. \& Cole, J. A. (2004). NapGH components of the periplasmic nitrate reductase of Escherichia coli K-12: location, topology and physiological roles in quinol oxidation and redox balancing. Biochem J 379, 47-55.

Dias, J. M., Than, M. E., Humm, A., Huber, R., Bourenkov, G. P., Bartunik, H. D., Bursakov, S., Calvete, J., Caldeira, J. \& other authors (1999). Crystal structure of the first dissimilatory nitrate reductase at $1.9 \AA$ A solved by MAD methods. Structure 7, 65-79.

González, P. J., Correia, C., Moura, I., Brondino, C. D. \& Moura, J. J. G. (2006). Bacterial nitrate reductases: molecular and biological aspects of nitrate reduction. J Inorg Biochem 100, 1015-1023.

Gross, R., Eichler, R. \& Simon, J. (2005). Site-directed modifications indicate differences in axial haem $c$ iron ligation between the related $\mathrm{NrfH}$ and NapC families of multihaem $c$-type cytochromes. Biochem $J$ 390, 689-693.

Hartley, A. M. \& Asai, R. J. (1963). Spectrophotometric determination of nitrate with 2,6-xylenol reagent. Anal Chem 35, 1207-1213.

Jepson, B. J. N., Marietou, A., Mohan, S., Cole, J. A., Butler, C. S. \& Richardson, D. J. (2006). Evolution of the soluble nitrate reductase: defining the monomeric periplasmic nitrate reductase subgroup. Biochem Soc Trans 34, 122-126.

Jepson, B. J. N., Mohan, S., Clarke, T. A., Gates, A. J., Cole, J. A., Butler, C. S., Butt, J. N., Hemmings, A. M. \& Richardson, D. J. (2007). Spectropotentiometric and structural analysis of the periplasmic nitrate reductase from Escherichia coli. J Biol Chem 282, 6425-6437.

Kröger, A., Geisler, V. \& Duchêne, A. (1994). Isolation of Wolinella succinogenes hydrogenase, Chromatofocusing. In A Practical Guide to Membrane Protein Purification, pp. 141-147. Edited by G. von Jagow $\&$ H. Schägger. London: Academic Press.

Kröger, A., Biel, S., Simon, J., Gross, R., Unden, G. \& Lancaster, C. R. D. (2002). Fumarate respiration of Wolinella succinogenes: enzymology, energetics and coupling mechanism. Biochim Biophys Acta 1553, 23-38.

Kyhse-Andersen, J. (1984). Electroblotting of multiple gels: a simple apparatus without buffer tank for rapid transfer of proteins from polyacrylamide to nitrocellulose. J Biochem Biophys Methods 10, 203209.

Lin, J. T. \& Stewart, V. (1998). Nitrate assimilation by bacteria. $A d v$ Microb Physiol 39, 1-30. 
Lorenzen, J. P., Kröger, A. \& Unden, G. (1993). Regulation of anaerobic respiratory pathways in Wolinella succinogenes by the presence of electron acceptors. Arch Microbiol 159, 477-483.

Marietou, A., Richardson, D., Cole, J. \& Mohan, S. (2005). Nitrate reduction by Desulfovibrio desulfuricans: a periplasmic nitrate reductase system that lacks $\mathrm{NapB}$, but includes a unique tetraheme c-type cytochrome, NapM. FEMS Microbiol Lett 248, 217-225.

Nilavongse, A., Brondijk, T. H. C., Overton, T. W., Richardson, D. J., Leach, E. R. \& Cole, J. A. (2006). The NapF protein of the Escherichia coli periplasmic nitrate reductase system: demonstration of a cytoplasmic location and interaction with the catalytic subunit, NapA. Microbiology 152, 3227-3237.

Olmo-Mira, M. F., Gavira, M., Richardson, D. J., Castello, F., MorenoVivián, C. \& Roldán, M. D. (2004). NapF is a cytoplasmic iron-sulfur protein required for $\mathrm{Fe}-\mathrm{S}$ cluster assembly in the periplasmic nitrate reductase. J Biol Chem 279, 49727-49735.

Palmer, T., Sargent, F. \& Berks, B. C. (2005). Export of complex cofactor-containing proteins by the bacterial Tat pathway. Trends Microbiol 13, 175-180.

Pfennig, N. \& Trüper, H. G. (1981). Isolation of members of the families Chromatiaceae and Chlorobiaceae. In The Prokaryotes, pp. 279-289. Edited by M. P. Starr, H. Stolp, H. G. Trüper, A. Balous \& H. G. Schlegel. Berlin: Springer Verlag.

Pittman, M. S., Elvers, K. T., Lee, L., Jones, M. A., Poole, R. K., Park, S. F. \& Kelly, D. J. (2007). Growth of Campylobacter jejuni on nitrate and nitrite: electron transport to NapA and NrfA via $\mathrm{NrfH}$ and distinct roles for $\mathrm{NrfA}$ and the globin $\mathrm{Cgb}$ in protection against nitrosative stress. Mol Microbiol 63, 575-590.

Potter, L. \& Cole, J. (1999). Essential roles for the products of the napABCD genes, but not napFGH, in periplasmic nitrate reduction by Escherichia coli K-12. Biochem J 344, 69-76.

Potter, L. C., Angove, H., Richardson, D. \& Cole, J. (2001). Nitrate reduction in the periplasm of Gram-negative bacteria. Adv Microb Physiol 45, 51-112.

Reyes, F., Gavira, M., Castillo, F. \& Moreno-Vivián, C. (1998). Periplasmic nitrate-reducing system of the phototrophic bacterium Rhodobacter sphaeroides DSM 158: transcriptional and mutational analysis of the napKEFDABC gene cluster. Biochem J 331, 897-904.
Richardson, D. J., Berks, B. C., Russell, D. A., Spiro, S. \& Taylor, C. J. (2001). Functional, biochemical and genetic diversity of prokaryotic nitrate reductases. Cell Mol Life Sci 58, 165-178.

Rider, B. F. \& Mellon, M. G. (1946). Colorimetric determination of nitrite. Indust Engin Chem 18, 96-98.

Rodrigues, M. L., Oliveira, T. F., Pereira, I. A. \& Archer, M. (2006). Xray structure of a membrane-bound cytochrome $c$ quinol dehydrogenase with novel heme ligation. EMBO J 25, 5951-5960.

Roldán, M. D., Sears, H. J., Cheesman, M. R., Ferguson, S. J., Thomson, A. J., Berks, B. C. \& Richardson, D. J. (1998). Spectroscopic characterization of a novel multiheme $c$-type cytochrome widely implicated in bacterial electron transport. J Biol Chem 273, 2878528790.

Sambrook, J., Fritsch, E. F. \& Maniatis, T. (1989). Molecular cloning: a Laboratory Manual, 2nd edn. Cold Spring Harbor, NY: Cold Spring Harbor Laboratory.

Simon, J. (2002). Enzymology and bioenergetics of respiratory nitrite ammonification. FEMS Microbiol Rev 26, 285-309.

Simon, J. \& Kröger, A. (1998). Identification and characterization of IS1302, a novel insertion element from Wolinella succinogenes belonging to the IS3 family. Arch Microbiol 170, 43-49.

Simon, J., Gross, R., Einsle, O., Kroneck, P. M. H., Kröger, A. \& Klimmek, O. (2000). A NapC/NirT-type cytochrome $c(\mathrm{NrfH})$ is the mediator between the quinone pool and the cytochrome $c$ nitrite reductase of Wolinella succinogenes. Mol Microbiol 35, 686-696.

Simon, J., Pisa, R., Stein, T., Eichler, R., Klimmek, O. \& Gross, R. (2001). The tetraheme cytochrome $c \mathrm{NrfH}$ is required to anchor the cytochrome $c$ nitrite reductase (NrfA) in the membrane of Wolinella succinogenes. Eur J Biochem 268, 5776-5782.

Simon, J., Sänger, M., Schuster, S. C. \& Gross, R. (2003). Electron transport to periplasmic nitrate reductase (NapA) of Wolinella succinogenes is independent of a NapC protein. Mol Microbiol 49, 69-79.

Simon, J., Einsle, O., Kroneck, P. M. H. \& Zumft, W. G. (2004). The unprecedented nos gene cluster of Wolinella succinogenes encodes a novel respiratory electron transfer pathway to cytochrome $c$ nitrous oxide reductase. FEBS Lett 569, 7-12.

Edited by: J. Moir 